EPIDEMIOLOGICAL REVIEW

\title{
Recent trends in the epidemiology of sexually transmitted infections in the European Union
}

\author{
K A Fenton, C M Lowndes, the European Surveillance of Sexually Transmitted Infections (ESSTI) \\ Network*
}

Sex Transm Infect 2004;80:255-263. doi: 10.1136/sti.2004.009415

Sexually transmitted infections (STIs) are a major public health problem in Europe. We review recent trends in the epidemiology of the major acute STIs in the European Union and Norway, their key determinants, and opportunities for enhancing STI prevention interventions in the region.

*See end of article for list of members.

See end of article for authors' affiliations

Correspondence to: Dr Kevin A Fenton, HIV/ STI Department, Health Protection Agency, Communicable Disease Surveillance Centre, 61 Colindale Avenue, London NW9 5EQ, UK

kevin.fenton@hpa.org.uk

Accepted for publication 3 May 2004
S exually transmitted infections (STIs) are a major public health problem in Europe. Their substantial morbidity, associated mortality, and disproportionate burden upon women, marginalised communities, and those with high risk sexual lifestyles ${ }^{1}$ continue to drive their prioritisation in European public health and policy arenas. ${ }^{2}$ In many European Union (EU) countries, widescale behavioural modification in response to the emerging HIV/AIDS pandemic saw dramatic reductions in the incidence of many acute STIs in the late 1980s..$^{3-6}$ However, these have not been maintained and many states are now observing increases in rates of diagnosed STIs. ${ }^{4}$ In this article we review recent trends in the epidemiology of the major acute STIs in the EU and Norway, their key determinants, and opportunities for enhancing STI prevention interventions in the region.

\section{METHODS}

We undertook a review of the published literature, STI surveillance reports, and ad hoc publications related to the distribution of STIs in the EU and Norway in order to describe recent trends in the epidemiology of major STIs in the region. Relevant publications were sought through computerised searches in PubMed from 1980 to 2002. Searches were not restricted by language. Internet searching was undertaken by visiting the websites of the national surveillance centres of all countries in the EU and where possible, collecting information on diagnoses of acute STIs. Where available, we obtained and analysed surveillance data for gonorrhoea, syphilis, and chlamydia for the 15 European countries provided by surveillance leads participating in the European Commission DG SANCO funded European STI Surveillance (ESSTI) Network. We also examined factors influencing the recent increases in STI rates and the contribution of different vulnerable populations to disease transmission. Finally, we accessed the grey literature in this area obtained through a network of STI physicians and epidemiologists. Conference abstracts and other unpublished manuscripts were excluded since the detailed information required was rarely available.

\section{REGIONAL DESCRIPTION: EUROPE - CHANGING DEMOGRAPHY AND IMPLICATIONS FOR STI TRANSMISSION}

At the time of writing, the EU comprised 15 member states (table 1), but on 1 May 2004, 10 accession countries (Cyprus, the Czech Republic, Estonia, Hungary, Latvia, Lithuania, Malta, Poland, Slovakia and Slovenia) joined the union. Data in this paper refer to the $15 \mathrm{EU}$ countries and Norway unless otherwise indicated. The EU's population of 379.0 million increased by 1290000 in 2002, an annual rate of $0.3 \% .^{7} \mathrm{Net}$ migration accounted for almost three quarters of this rise (table 2). Population increases were largest in Ireland (15.2 per 1000) and Luxembourg (9.5 per 1000) and lowest in Germany (1.2 per 1000) and Italy (1.4 per 1000). Net migration was higher than the natural increase in every member state in 2002, apart from France, Ireland, the Netherlands, and Finland (table 2).

The natural increase in the EU has been below net migration since 1989. The declining natural increases in many EU states are largely explained by women having fewer than two children on average coupled with an increasing average age at childbirth. ${ }^{78}$ The total fertility rate in the EU in 2002 remained virtually unchanged at 1.47 children per woman compared with 2001 and 2000. The highest fertility rates are recorded by Ireland (2.01) and the lowest by Greece, Spain (1.25 each), and Italy (1.26). Marriages continue to decline in the EU, falling from 2.2 million in 1980 to 1.8 million in $2002(-19 \%)$. Demographic trends towards earlier coitarche, later childbirth, and declining marriage will have implications for sexual health as they widen the time period available for sex partner acquisition, a key determinant of STI transmission.

Immigration, whether the result of family reunification, economic migration, or asylum seeking, has become an increasingly visible and explosive issue in many western European nations $^{79}$ (tables 1 and 2). The EU is still a major recipient of asylum applications although

\footnotetext{
Abbreviations: CISID, WHO Computerized Information System for Infectious Diseases; EU, European Union; HPV, human papillomavirus; NAATs, nucleic acid amplification tests; PCR, polymerase chain reaction; STI, sexually transmitted infections
} 


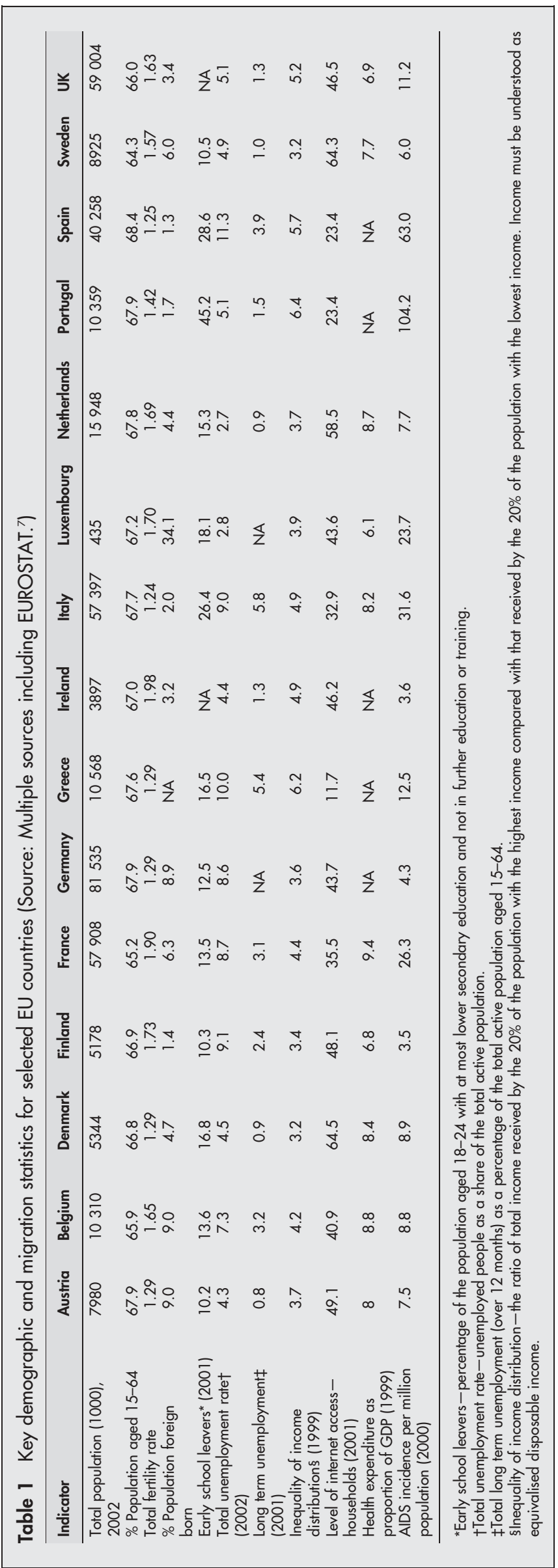


Table 2 Population movements and asylum applications in EU, 2001

\begin{tabular}{|c|c|c|c|c|c|c|c|}
\hline \multirow[b]{2}{*}{ Country } & \multicolumn{5}{|c|}{ Population movements 2002, per 1000 inhabitants } & \multicolumn{2}{|c|}{$\begin{array}{l}\text { Asylum applications submitted in } 2001 \text { (countries with more than } \\
10000 \text { applications) }\end{array}$} \\
\hline & Births & Deaths & $\begin{array}{l}\text { Natural } \\
\text { population } \\
\text { growth }\end{array}$ & $\begin{array}{l}\text { Net } \\
\text { migration }\end{array}$ & $\begin{array}{l}\text { Total } \\
\text { increase }\end{array}$ & Total & Main countries or origin \\
\hline EU-15 & 10.6 & 9.7 & 0.8 & 2.7 & 3.6 & & \\
\hline Austria & 9.6 & 9.2 & 0.4 & 2.1 & 2.5 & 30140 & Afghanistan, Iraq, Turkey, India, Yugoslavia \\
\hline Belgium & 11.0 & 10.4 & 0.6 & 2.9 & 3.5 & 24550 & Russian Fed. Yugoslavia, Algeria, D.R. Congo, Iran \\
\hline Denmark & 11.9 & 10.9 & 1.0 & 2.6 & 3.6 & 12400 & $\begin{array}{l}\text { Afghanistan, Iraq, Bosnia-Herzegovia, Yugoslavia, } \\
\text { Somalia }\end{array}$ \\
\hline Finland & 10.6 & 9.4 & 1.3 & 1.1 & 2.4 & NA & NA \\
\hline France & 12.9 & 8.9 & 4.0 & 1.0 & 5.0 & $47290^{*}$ & Turkey, D.R. Congo, China, Mali, Algeria \\
\hline Germany & 8.8 & 10.2 & -1.4 & 2.8 & 1.4 & 88,290 & Iraq, Turkey, Yugoslavia, Afghanistan, Russian Fed. \\
\hline Greece & 9.0 & 9.4 & -0.4 & 3.2 & 2.8 & NA & NA \\
\hline Ireland & 14.8 & 7.7 & 7.1 & 5.1 & 12.2 & 10330 & Nigeria, Romania, Moldova, Ukraine, Russian Fed, \\
\hline Italy & 9.6 & 9.9 & -0.3 & 2.7 & 2.3 & NA & NA \\
\hline Luxembourg & 11.9 & 8.3 & 3.6 & 6.7 & 10.3 & NA & NA \\
\hline Netherlands & 12.5 & 8.8 & 3.8 & 1.8 & 5.5 & 32580 & Angola, Afghanistan, Sierra Leone, Iran, Guinea \\
\hline Portugal & 10.7 & 10.4 & 0.3 & 6.7 & 7.0 & NA & NA \\
\hline Spain & 10.4 & 9.2 & 1.2 & 5.6 & 6.8 & NA & NA \\
\hline Sweden & 10.6 & 10.6 & 0.0 & 3.7 & 3.7 & 23520 & $\begin{array}{l}\text { Iraq, Yugoslavia, Bosnia-Herzegovina, Iran, FYR } \\
\text { Macedonia }\end{array}$ \\
\hline UK & 11.2 & 10.2 & 0.9 & 1.8 & 2.7 & 88300 & Afghanistan, Iraq, Somalia, Sri Lanka, Yugoslavia \\
\hline
\end{tabular}

the number of applications in 2001 fell by $2 \%$ compared with 2000 (from 391460 to 384 530). The main factors influencing people's migration behaviour include labour market conditions, availability and price of housing, environmental and quality of life considerations, and the effects of government policies. International migration may pose a particular challenge for sexual health as individuals may arrive from, or have contact with, high STI/HIV prevalence countries of origin, thereby increasing their own STI acquisition risk.

\section{INFRASTRUCTURE FOR STI DIAGNOSIS, TREATMENT AND SURVEILLANCE - IMPLICATIONS FOR EU COMPARATIVE STUDIES}

There is currently no single, comprehensive source of information on the incidence of, and trends in, diagnosed STIs in the EU. The overall picture has to be assembled from sources that vary in their coverage, detail, and accuracy. In part this reflects the wide variations in STI treatment and care services across the region (see accompanying paper by Lowndes $\left.e t a l^{10}\right)$. The United Kingdom is unique in having a dedicated network of treatment centres solely for the management of acute STIs (genitourinary medicine or GUM clinics), from which statistical returns form the basis of national STI surveillance programmes. Data on STIs diagnosed outside of this setting are captured by laboratory reporting or special sentinel surveillance programmes. In contrast, in other EU states, a varying combination of specific STI services, dermato-venereology, public health, and general practice clinics form the basis of STI diagnosis and care, with surveillance data being obtained through voluntary or mandatory reporting from clinics or laboratories; with sentinel or comprehensive coverage.

Lowndes et $a l^{10}$ in a cross sectional survey of EU STI surveillance systems confirm this heterogeneity, whereas comprehensive STI case reporting from dedicated STI treatment centres is the norm in the United Kingdom, and mandatory reporting is required from STI treatment sites Scandinavia, many other EU states rely on a combination of sentinel reporting, mandatory disease notification, or laboratory reporting to monitor disease trends. Considerable variation also exists in the case definitions for the major acute STIs, with some countries requiring laboratory confirmed reports while others require clinical diagnoses or

Table 3 Recent trends in gonorrhoea and syphilis reports among EU countries

\begin{tabular}{|c|c|c|c|c|c|c|c|c|c|c|}
\hline \multirow[b]{2}{*}{ Country } & \multicolumn{5}{|c|}{ Gonorrhoea } & \multicolumn{5}{|c|}{ Syphilis } \\
\hline & 1991 & 1995 & 2000 & $\begin{array}{l}\% \text { change } \\
1991-5\end{array}$ & $\begin{array}{l}\% \text { change } \\
1995-2000\end{array}$ & 1991 & 1995 & 2000 & $\begin{array}{l}\% \text { change } \\
1991-5\end{array}$ & $\begin{array}{l}\% \text { change } \\
1995-2000\end{array}$ \\
\hline Austria* & 1750 & 896 & 414 & -48.8 & -53.8 & 161 & 180 & 237 & 11.8 & 31.7 \\
\hline Belgium* & 267 & 130 & 145 & -51.3 & 11.5 & 56 & 30 & 90 & -46.4 & 200 \\
\hline Denmark* $†$ & 1326 & 287 & 335 & -78.4 & 16.7 & 62 & 42 & 54 & -32.3 & 28.6 \\
\hline Finland $^{*} \dagger$ & 1426 & 378 & 284 & -73.5 & -24.9 & NA & 138 & 198 & & 43.5 \\
\hline Germany* & NA & NA & NA & - & - & 1268 & 1138 & NA & -10.3 & - \\
\hline Greece† & 118 & 117 & 98 & -0.8 & -16.2 & NA & NA & NA & & \\
\hline Ireland $†$ & 73 & 91 & 290 & 24.7 & 218.7 & 20 & 11 & 48 & -45.0 & 336.4 \\
\hline Netherlands* $†$ & 2900 & 1425 & NA & -50.9 & & 253 & 204 & NA & -19.4 & \\
\hline Portugal $^{*} \dagger$ & 239 & 73 & 46 & -69.5 & -37 & 218 & 218 & 175 & 0.0 & -19.7 \\
\hline Spaint & 11428 & 4599 & 1045 & -59.8 & -77.3 & 1509 & 1010 & 700 & -33.1 & -36.7 \\
\hline Sweden* & 617 & 246 & 590 & -60.1 & 139.8 & 118 & 69 & 99 & -41.5 & 43.5 \\
\hline UK† & 17666 & 10598 & 21131 & -40.0 & 99.4 & 367 & 141 & 327 & -61.6 & 131.9 \\
\hline
\end{tabular}

*Source: CISID - the Computerized Information System for Infectious Diseases. ${ }^{73}$

†Source: Data provided by National STI Surveillance Leads, see Methods. 
syndromes. Variations in STI screening, partner notification and treatment practices also influence the degree to which asymptomatic patients and sexual contacts are diagnosed, treated, and recorded in surveillance statistics. Finally, many EU STI surveillance systems are in a state of flux with some countries recently abolishing or developing new national programmes. The net result of this heterogeneity is a severe limitation in our ability to compare disease rates across EU states and in some instances, to monitor disease trends within countries.

\section{DESCRIPTION OF OVERALL TRENDS}

However, despite these differences, a number of broad similarities in STI incidence and trends can still be observed across the EU. Most striking is the general reduction in rates of acute bacterial STIs which occurred across the EU throughout the 1980s and early 1990s. ${ }^{3}$ Gonorrhoea reports fell by between $40-70 \%$ in most western EU states between 1991 and 1995, and syphilis reports fell between 10-60\% in most states (table 3). These decreases coincided with the emergence of the global HIV/AIDS pandemic, and have been attributed to population-wide behavioural modification in response to HIV campaigns during that time. The disproportionate impact of AIDS related mortality on high risk population subgroups may have also contributed to these decreases. ${ }^{11}$

Numbers and rates of acute STIs in many EU countries have however again been on the increase since the mid1990s. In the United Kingdom, Ireland, and Sweden, diagnoses of gonorrhoea have more than doubled since 1995 and similar magnitude of increases in syphilis reports have been observed in Belgium, the United Kingdom, and Ireland (table 3). Increasing diagnoses of either infection, although of lower magnitude, have been recorded in Spain, Denmark, Austria, France, Finland, Netherlands, and Sweden. The increases have occurred across a range of constituencies but have been most marked among young people, homosexual men, and those resident in major metropolitan areas.

Variations in STI incidence have also been described within some migrant and ethnic minority communities in some EU states, reflecting high disease prevalence in their countries of origin; higher prevalence of risk behaviours; and generally poor access to culturally appropriate STI prevention and treatment services. Finally, many EU states continue to experience evolving commercial sex work networks, partially driven by changing migratory patterns, human trafficking, and illegal drug use. These will continue to offer new opportunities for STI transmission.

\section{DISEASE SPECIFIC TRENDS Gonorrhoea}

A decline in gonorrhoea rates was noted in most western EU countries starting in the $1970 \mathrm{~s}^{5} 5^{12}{ }^{13}$ with acceleration in the rates of decline during the second half of the 1980s. Much of this decline continued into the early 1990s. Table 3 summarises gonorrhoea reports from selected EU countries (compiled from national surveillance and WHO databases) between 1990 and 2000, and confirms the near uniform decreases in disease incidence during the first half of this period. By 1995, gonorrhoea rates reach their lowest point in many EU states.

However, EU-wide increases in diagnoses and rates of gonorrhoea have been observed since the late 1990s (table 3). In Belgium, gonorrhoea incidence has increased consistently since 1997. The incidence in men aged 25-44 years rose from 3 per 100000 population in 1995, to 3.5/100 000 in 1997 and 5/100 000 in 1998. ${ }^{14}$ In England, Wales, and Northern Ireland gonorrhoea diagnoses more than doubled between 1996 and
2001 with $40 \%$ of diagnoses among women occurring in those aged under 20 years. In France, the RENAGO (Réseau National du Gonocoque) network reported an almost twofold increase in the number of patients diagnosed with gonorrhoea between 1997 and 1998, reversing a trend observed since $1987 .{ }^{14}$ In Ireland there was a $320 \%$ increase in notified gonorrhoea cases between 1996 and 2001, with 83 (2.3/ $100000)$ in 1996 and $349(8.9 / 100000)$ in 2001; 75.9\% of cases in 2001 were in men. In Austria, the number of notified gonococcal cases increased from 414 in 2000 to 995 in 2002 with an increase in both men and women. Statutory notification of gonorrhoea began in Spain in 1982 and has fallen continuously since the disease became notifiable. From 1993 to 1999 the rates fell from 18.6 to 3.9 cases per 100000 population. $^{14}$

Not all countries have been observing these marked increases. In Norway the number of cases of gonorrhoea reported by laboratories fell steadily from 944 cases in 1990 to 175 in 1995, rose to 223 in 1996, but has remained below 200 since then. ${ }^{14}$ In Sweden, between 1997 and 2000, increasing number of cases were seen. This trend was reversed in 2001 with a decrease in number of cases, followed by a further decrease in 2002 leading to an infection rate of 5.6/100 000 population. There has however been a noted increase in cases reported in the first half of 2003 compared with the same period in 2002..$^{15}$

In many EU states, gonorrhoea incidence is concentrated among the young, homosexual men, highly sexually active, and socioeconomically deprived communities. In England Wales, and Northern Ireland, $40 \%$ of all gonorrhoea diagnoses in women occur in those aged 16-19 years, and $17.4 \%$ of all diagnoses in men are acquired through sex between men. ${ }^{17}$ In Sweden $44.8 \%$ of the gonorrhoea cases in 2002 were among men who have sex with men (MSM). In Denmark $^{18}$ Johansen and Smith confirmed that MSM account for a disproportionately large burden of gonorrhoea in that country with the highest incidence occurring among HIV infected MSM (483.3 per 100000 population per year) compared to others. There is also a strong association between infection and overseas travel.

Data on gonococcal antimicrobial resistance across the EU is not comprehensive, and this remains an area for future investment. Van Duynhoven ${ }^{5}$ found that plasmid mediated resistance to penicillin and tetracycline had increased in Europe during the early 1990s. At that time, sporadic resistance to fluoroquinolones had been documented, mainly imported from South East Asia with no resistance to third generation cephalosporins being observed. ${ }^{5}$ By the mid1990s, high levels of penicillin positive Neisseria gonorrhoeae (PPNG) were reported in many large metropolitan areas across Europe with prevalences of 13\% in Sweden, 6\% in Finland, 3\% England, 14\% in France, and 15-30\% in the Netherlands. More recently, increases in flouroquinolone resistance have been reported in many EU states. In Denmark, laboratory confirmed prevalence of fluoroquinolone resistance increased from $0 \%$ to $27 \%$ in $1999,{ }^{19}$ while $17 \%$ of strains were resistant to both penicillin and fluoroquinolones. ${ }^{19}$ In Austria, an increase of the resistance to ofloxacin and ciprofloxacin has been documented from $0 \%$ and $3.1 \%$, respectively, in 1999 , to $52.3 \%$ and $48.8 \%$, respectively, in 2002. Data from the Gonococcal Resistance to Antimicrobials Surveillance Programme (GRASP) in England and Wales also confirm recent increases in ciprofloxacin resistance. In 2002, 2204 gonococcal isolates were tested, and the overall prevalence of ciprofloxacin resistance (minimum inhibitory concentration $>$ or $=1 \mathrm{mg} / \mathrm{l}$ ) was $9.8 \%$, compared with $3.1 \%$ in 2001 and $2.1 \%$ in 2000 . Similar increases were reported in Scotland (11\% in 2002 compared with $4 \%$ in 2001 and $2.8 \%$ in 2000). In Sweden a national 
prevalence study in 1998 tested 348 isolates, representing $89 \%$ of diagnosed cases in Sweden, showed $18 \%$ of all isolates to have a decreased susceptibility to ciprofloxacin (MIC $>0.64 \mathrm{mg} / \mathrm{l})$. This percentage was substantially higher (63\%) among individuals who had been exposed in Asia. ${ }^{20}$

\section{Syphilis}

As with gonorrhoea, numbers and rates of infectious syphilis fell to their lowest levels in many EU countries by the early $1990 \mathrm{~s}^{6}$ (table 3 and fig 1). ${ }^{21}$ This was despite concomitant and dramatic increases in syphilis incidence in the former USSR. ${ }^{22}$ The decreases were accompanied by marked reductions in the incidence of congenital syphilis and tertiary disease. In 1995, with the exception of Germany with 1138 reports, fewer than 300 cases of infectious syphilis were reported in any of the other reporting EU countries (table 3). Among these, endemic transmission was rare, with the majority of infections being diagnosed among migrants from high prevalence countries or among EU nationals who had sexual contact outside of the region.

Since 1996, syphilis has again been on the increase in many northern and western EU states. Several outbreaks of infectious syphilis have arisen in cities across the United Kingdom since the mid-1990s. These have affected homosexual men, heterosexual men and women, newborns, commercial sex workers, and drug users. ${ }^{23}{ }^{24}$ In Paris, increases in infectious syphilis cases (30 in 2000 to over 200 in 2002) led to the extension of the Paris syphilis screening campaign to selected French towns and cities targeted at MSM. ${ }^{25}$ In Belgium, between 2000 and 2002, a 3.5-fold increase in number of laboratory diagnosed syphilis cases was detected by sentinel networks of laboratories. The increases were observed mainly among male patients. ${ }^{26}$ In Rotterdam, the 56 cases of infectious syphilis (including primary, secondary, early latent) were diagnosed in 2002, compared with 24 cases in 2001 and 16 in 2000. ${ }^{27}$ In Denmark $^{28}$ a total of 54 and 51 cases of infectious syphilis were detected during 2000 and 2001, including two cases of congenital syphilis, a substantial increase compared to 1999 when 34 cases were detected. In Finland ${ }^{22}$ a local cluster or 18 cases was detected in the city of Tampere, the majority of whom were associated with travel to Russia, Estonia, or elsewhere. In Austria, the notified number of syphilis cases steadily increased from 124 in 1993 to 420 in 2002, with about $70 \%$ of cases reported in Vienna. In Germany the incidence of syphilis declined significantly throughout the

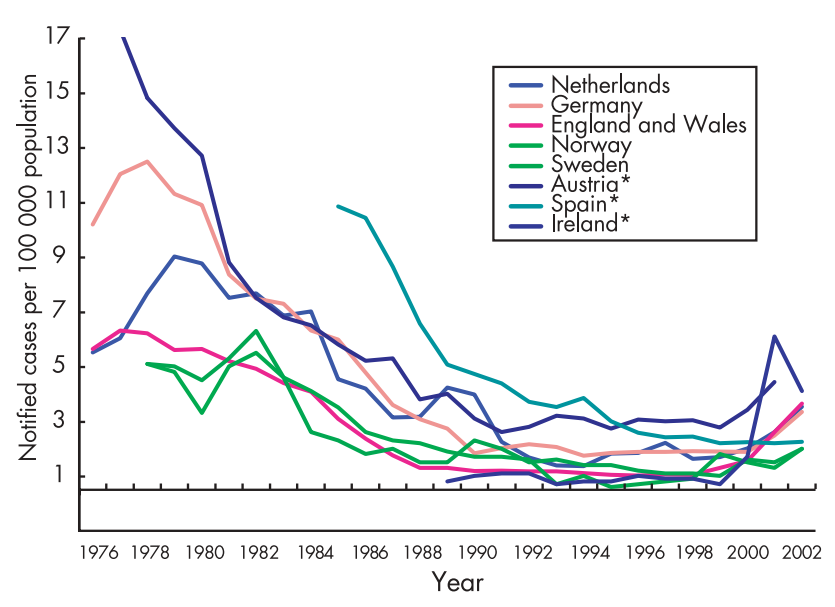

Figure 1 Notifications of infectious syphilis in selected EU countries and Norway. Data from the WHO Computerized Information System for Infectious Diseases (CISID) ${ }^{73}$ and national surveillance databases. ${ }^{31}$ 1990s ranging between 1.2-1.7 per $100000{ }^{29}$ Annual syphilis notifications for the years 1995 to 2000 had been in the range of 1120-1150. In 2001 the syphilis notification system was changed from a mandatory physician based system to laboratory based notification. In 2001, 1681 cases were reported and there were 1102 cases reported in the first 6 months of 2002. ${ }^{30}$ Much of these increases occurred in large metropolitan German cities.

In Ireland, there has been a dramatic increase in syphilis among MSM in Dublin since early 2000. This was against a low incidence of syphilis nationally throughout the 1990s, which in 1999 reached its lowest level in 10 years (six cases, $0.2 / 100000$ ). An enhanced surveillance system for syphilis was set up in 2000, with 48 infectious cases (1.2/100 000) reported in 2000, 219 cases (5.6/100 000) in 2001, and 142 cases (3.6/100 000) in 2002. ${ }^{31}$ In Norway, a reported outbreak in Oslo among homosexual men (40 cases) contributed to much of the increase in the national incidence rate for 1999, and rates have continued to increase since. In Sweden there was a considerable increase of syphilis cases in 2000 (99 cases) followed by a decrease in 2001, 77 cases of acquired syphilis and one case of congenital syphilis. However, there was an increase in 2002 when 127 cases of acquired syphilis and one case of congenital syphilis were reported; $81 \%$ were in men, and among them $71 \%$ were in MSM. In 2002, 44\% of the infections were acquired abroad, some among asylum seekers and immigrants from high prevalence areas, but also among men involved in homosexual activity abroad. The increase also continued in the first half of 2003 when 85 cases were reported, an increase of $107 \%$ compared with the same period in 2002.

Among homosexual men, the resurgence of syphilis has been associated with increasing high risk sexual behaviour, novel sexual networks, use of recreational drugs such as ecstasy and gamma hydroxybutyrate (GHB), sexual activity overseas, and HIV co-infection. ${ }^{32}{ }^{33}$ Among heterosexuals risk factors have included sexual activity overseas, migration from high prevalence countries, commercial sex work contact, and drug use. Management of these outbreaks has centred on active partner notification, the establishment of enhanced surveillance of infectious syphilis in the affected areas, and investigation of social and sexual networks facilitating disease transmission. Interventions include enhancing public and healthcare worker awareness of syphilis, venue based screening, rapid testing within and outside of STI treatment

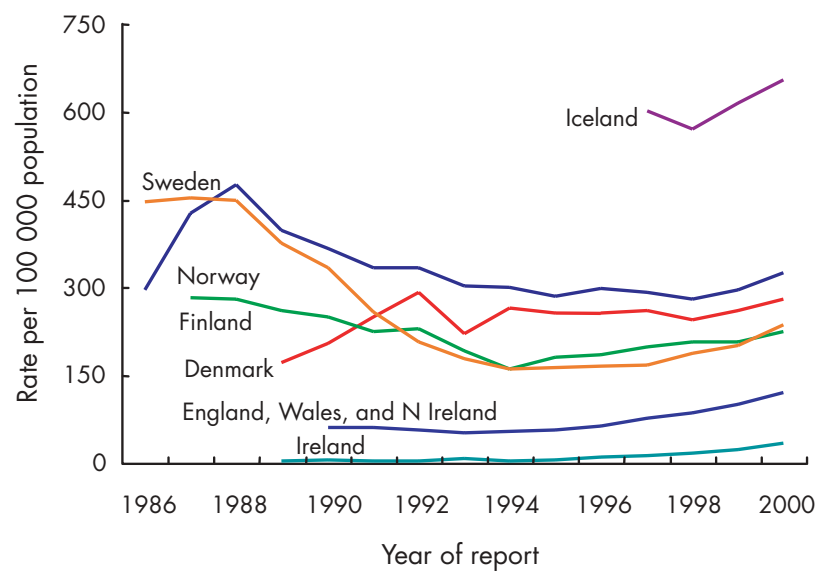

Figure 2 Trends in rates of genital chlamydial infection in selected EU countries and Norway. Data from the WHO Computerized Information System for Infectious Diseases (CISID) ${ }^{73}$ and national surveillance databases. ${ }^{31}$ 
centres, targeted sexual health promotion, and syphilis screening of HIV positive individuals.

\section{Genital chlamydial infection}

Clinical case notification of genital chlamydial infection is not mandatory in the majority of EU countries and therefore relatively little information is available from national surveillance sources. In the EU countries collecting this information, genital chlamydial infection is now among the most commonly diagnosed bacterial STIs and broadly increasing trends in diagnoses have been observed since the mid-1990s (see fig 2). The surveillance data also confirm the disproportionate disease burden occurring in young women aged less than 20 years. The increasing notification rates are however confounded by concomitant increases in screening rates for this infection and also the increasing use of the highly sensitive nucleic acid amplification tests (NAATs).

In Denmark, approximately 13 000-14 000 cases of laboratory confirmed genital chlamydia were reported annually during the past decade. By 1999, the highest age specific incidence occurred in the 20-24 year age group among men (950 per 100000 ) and in women (2477 per 100000$).{ }^{19}$ By 2001, 15150 cases of chlamydia were diagnosed - an annual incidence of 283 per 100 000. In Ireland, from 1989 to 1995 the number of notified cases of chlamydia generally remained stable, fluctuating around 200 cases per year. In 1995 there was a marked increase of $84.2 \%$ on the previous year (from 133 case, 3.7/100 000 to 245 cases, 6.8/100 000). Since then there has been an increasing number of cases reported each year reaching 1649 in 2001. Between 2000 and 2001 the number of male and female cases increased by $15.6 \%$ and $28.4 \%$ respectively.

In Norway, cases of chlamydia (laboratory notifications) showed a slight decrease from 1986-98 with there being around 12500 cases in 1998. The peak of reported cases was in 1988 with nearly 20000 cases being reported. In Sweden, there was a decrease in cases from approximately 350/ 100000 inhabitants in 1989 to $160 / 100000$ each year from 1993 to 1997. Since 1997 there was an increase in cases. In 2002 there were 276/100 000, this represents the same level of infection as 10 years ago and is an $11 \%$ increase on 2001 . In England, Wales, and Northern Ireland, the number of uncomplicated chlamydia diagnoses in GUM clinics has risen steadily since the mid-1990s and rose by 14\% (71 909 to 81680 ) between 2001 and 2002, a rise of $13 \%$ in females and $15 \%$ in males. In 2002, the highest rates of chlamydia were among 16-19 year old females (1201/100 000) and 2024 year old males $(837 / 100000)$. Rates in both males and females were highest in the London region (272 and 271/ 100000 respectively). In Scotland, laboratory reported cases of chlamydia increased by 17\% (10 636 to 12392) between 2001 and 2002-the increase was 16\% in males and 20\% in females. ${ }^{31}$ In a large STI diagnostic centre in Vienna the number of chlamydia cases among about 25000 men and women annually tested increased slightly from $2.3 \%$ in 1995 to $3.4 \%$ in $2002 .^{31}$

Because of frequently asymptomatic nature of infections, our understanding of chlamydial epidemiology in Europe is also greatly enhanced by data from ad hoc prevalence studies. Wilson et $a l,{ }^{34}$ in a systematic review of chlamydia prevalence in asymptomatic women, found that the prevalence of $C$ trachomatis in unscreened asymptomatic women in Europe ranging from $1.7 \%$ to $17 \%$ depending upon the setting, context and country (fig 2). ${ }^{34}$ The mode was $6 \%$ for women seeking contraception and $4 \%$ for women having cervical smears. In Vienna, asymptomatic urethral chlamydia infections were observed in young male military recruits in $4.1 \%$ when testing urine using nucleic acid amplification techniques. ${ }^{35}$

\section{Genital herpes}

In general, viral STIs are not notifiable in most EU countries ${ }^{10}$ and relatively few surveillance data are available published on viral STIs in the EU. Where available, increasing trends, albeit at lower rates compared to bacterial STIs, have been described. Genital herpes simplex virus (HSV) infection is the most common ulcerative sexually transmitted infection (STI) in the United Kingdom. Between 1972 and 2002, the number of genital HSV diagnoses made at GUM clinics increased twofold and ninefold in males and females, respectively. The number of diagnoses stabilised and fell briefly in the mid1980s possibly because of changes in sexual behaviour following extensive media coverage of AIDS. In 2002, 18392 new cases were reported in England, Wales, and Northern Ireland. For females and males, highest rates were seen in the 20-24 year olds; 2053 per 100000 population and 93 per 100000 respectively. In Ireland in 2001, notified cases of genital herpes simplex virus increased by $23.0 \%$ on the previous year. HSV cases increased from 78 (2.2/100 000) in 1989 to $198(5.5 / 100000)$ in 1995 and 331 (8.5/100 000) in 2001. Between 1995 and 2001, the highest rates per 100000 population were consistently in females and where age group was known, in 20-29 year olds.

In many European countries, seroepidemiological studies provide some insight into the cumulative incidence and prevalence of HSV infection. They confirm the strong association between HSV-2 seroprevalence and increasing age, number of partners during the previous year, as well as the increasing proportion of first episodes of genital herpes being caused by HSV-1 rather than HSV-2. This is especially so among female patients and in the younger age groups with primary or initial disease, where HSV-1 may be the causative viral type in up to $70-90 \%$ of cases. The documented change from HSV-2 towards HSV-1 in cases of genital HSV infection may have implications as to prognosis, usefulness of vaccines, and usefulness of new type specific serological tests.

Smith and Robinson ${ }^{36}$ reviewed published type specific HSV seroepidemiological surveys and found striking variations in HSV-2 prevalence in western Europe. They found HSV-2 prevalence to be higher in northern Europe and North America than in western and southern Europe. The highest prevalence of HSV-2 infection was found among women in Greenland: $57 \%$ among those aged 20-24 years and rising to $74 \%$ in those $25-39$ years. ${ }^{37}$ In Scandinavia, HSV-2 prevalence was relatively higher than in other areas of Europe, about $15 \%-35 \%$ among women aged $25-35$ years. ${ }^{37-41}$ Three studies in Finland estimated HSV-2 prevalences of 16\%, 26\%, and $31 \%$ among women with mean ages of 30,39 , and 44 years, respectively, ${ }^{42-44}$ although the studies differed by population, location, and date. In one German study, ${ }^{45}$ HSV-2 infection was lower among male and female blood donors and hospital patients but was $>20 \%$ among men and women $\geqslant 60$ years.

In Spain, HSV-2 prevalence appeared low $(2 \%-6 \%)$ in a large sample of male and female $14-17$ year olds, ${ }^{46}$ in men and women 15-45 years old in eight different geographic areas,${ }^{47}$ and in Madrid women. ${ }^{48}$ In Italy, age specific HSV-2 prevalence was low $(0.1 \%)$ in a national sample of young male draftees aged 18-25 years, [49. 50] in patients (median age, 26 years) attending a hepatitis $\mathrm{B}$ immunisation centre $(1.1 \%),{ }^{49}{ }^{50}$ and in health professionals (mean age, 30 years; $4.8 \%)$. In the United Kingdom, HSV-2 prevalence in the general population is low, with the rate of infection significantly lower than that described for the general population in other areas of northern Europe and the United States. In a national UK sample, HSV-2 prevalence was $4.7 \%$ among women aged $20-44$ years who were controls in a cervical cancer study. ${ }^{51}$ In this study and in the remaining UK studies, HSV-2 prevalence was $<9 \%$ for women and men in all age groups. 


\section{Genital warts}

The most commonly identified manifestations of genital human papillomavirus (HPV) infection are anogenital warts, condyloma acuminata. ${ }^{52}$ HPV types 6 and 11 , responsible for the majority of visible anogenital warts, are commonly regarded as being of low risk with regard to malignancy, and are estimated to affect $1 \%$ of sexually active adults aged between 15 and $49 .{ }^{52}$ Nevertheless, few EU countries routinely collect surveillance data on genital warts infections. In England, Wales, and Northern Ireland, anogenital warts (including new, recurrent and re-registered cases) are the most common viral STI diagnosed at GUM clinics, comprising $10 \%$ (69 417 of 675170 ) of all diagnoses in 2002. Highest rates of new cases were found in 20-24 year old males (776/ $100000)$ and in 16-19 year old females (681/100 000). In Ireland, anogenital warts accounted for $41.2 \%$ of all STI notifications in 2001. Anogenital warts notifications have increased each year since 1992. In 1989, 505 (14.3/100 000) cases were notified, increasing to $1972(54.4 / 100000)$ cases in 1995 and 3993 cases (101.9/100 000) in 2001. In 2001, 48.8\% (1947) of cases were male and 51.2\% (2044) were female.

Little is known about the prevalence of HPV in the general population. Routine surveillance data and prevalence studies measuring clinical manifestations of HPV (warts, dysplasia, malignancy) will miss asymptomatic and subclinical infections of the genital tract..53 Overall HPV prevalence estimates are also dependent on the age of the sample, the population being sampled, methods used to take clinical specimens, and the polymerase chain reaction (PCR) amplification techniques employed (in particular, which primers are included) ${ }^{54}$ Whereas many studies report declining HPV prevalence with age, ${ }^{55-58}$ others have found no age related trend in HPV prevalence or even an indication of an opposite trend. ${ }^{59}{ }^{60} \mathrm{~A}$ population based cohort study carried out in Sweden in 1989 found a baseline HPV prevalence of $22 \%$ among sexually active women aged 19-25 (PCR techniques used). ${ }^{59}$ Studies of women attending routine cervical screening in the United Kingdom in the 1990s have estimated prevalence of HPV "high risk" types of around 6-7\%. ${ }^{56}{ }^{61}$

Other studies have tended to survey convenience samples of women, usually comprising or including women undergoing gynaecological examination, and thus likely to overrepresent women at higher risk. ${ }^{62}$ A cross sectional study of young Finnish army conscripts (mean age 20) carried out in 1992 found 26\% to have any evidence of penile HPV infection (PCR techniques used), although study participants were biased in reporting more sexual risk behaviours or GU symptoms than non-participants. ${ }^{63}$ Similar prevalence estimates were obtained in a study of Swedish army conscripts (18-23 years), $24 \%$ of whom were HPV positive using a variety of detection methods (dot/Southern blot hybridisation and PCR). ${ }^{64}$ As only half of the conscripts approached agreed to participate, this prevalence may not be reflective of the entire group. A study carried out in Germany in the mid1980 s tested penile swabs obtained from blood donors without signs of genital disease using filter in situ hybridisation techniques and found an overall HPV prevalence of $5.1 \%$ in those aged 16-35, and $1.4 \%$ prevalence of types $16 / 18 .^{65}$ Both the selection criteria and the testing methods applied are likely to make this last study underestimate the prevalence of penile HPV infection in the male population.

\section{DRIVING FACTORS}

The consistency of trends across the EU would suggest that, at the macro level, major societal and behavioural determinants of STI transmission are operating in tandem. Those related to the changing demographic, social, and economic structure of the EU (decreases in marriage, delayed childbirth, population movement) have been mentioned previously and will continue to be major influences in the future. Sexual behaviour is, nevertheless, the key determinant of STI transmission and EU-wide changes in the patterns and distribution of high risk sexual behaviour are undoubtedly contributing to the changing disease epidemiology. In many EU countries, the age at first intercourse has stabilised or continues to decline. Data from the recently completed second British National Survey of Sexual Attitudes and Lifestyles (Natsal 2000) confirm the widespread increases in rates of partner acquisition, inconsistent condom use; and homosexual sexual behaviour in the British population over the past decade. ${ }^{66}$ Targeted behavioural surveillance surveys (BSS) have also confirmed worsening high risk behaviour among homosexual men in some EU states, with rising trends in reported unprotected anal intercourse being observed in both HIV negative and positive MSM. ${ }^{86} 69$ Similar BSS within young people, migrant communities, and HIV positive individuals will be needed to better interpret disease trends in these groups.

Technological developments are also improving our ability to diagnose and report STIs across the EU. The increasing availability of highly sensitive and specific NAATs, rapid diagnostic tests, and near patient testing for bacterial STIs are improving the ascertainment of infections such as genital chlamydia. Simultaneously, changes in STI screening and diagnostic testing outside of traditional settings are now being advocated in many EU countries and will also contribute to the increasing trend.

Surveillance developments, such as the new sentinel surveillance systems being introduced in Germany, Netherlands, Spain, and Portugal will continue to improve ascertainment and increase STI reports. A review of STI surveillance in Ireland, which is currently under way, together with imminent legislative change and the planned introduction of a national computerised infectious disease reporting (CIDR) system, will greatly improve the quality of the available STI surveillance data.

\section{OPPORTUNITIES FOR SEXUAL HEALTH GAIN}

Given the current changes in disease epidemiology, it is clear that considerable health gain is to be obtained from greater investment in effective STI treatment, diagnosis, prevention, and surveillance in all EU countries. At the country level, this must begin by increasing political commitment to sexual health and with the provision of strategic leadership at the highest level. In England, the recent publication of a national sexual heath and HIV strategy, ${ }^{70}$ the appointment of an Independent advisory committee on sexual health, and parliamentary enquiries into sexual health services and migration and $\mathrm{HIV}^{72}$ have served to raise sexual health on the political and public agenda. Nevertheless, much remains to be done. Similar strategies are now being developed in Scotland, Wales, Norway, and Sweden.

Continued investment in STI (including HIV) prevention, microbiological, and surveillance research is also required. Specifically, recent reviews of effectiveness of HIV and STI prevention should be used to guide and prioritise investment in this area. Gains are also likely to be achieved through harnessing the collective expertise and promoting collaboration between laboratory, surveillance, clinical and public health colleagues. The evidence suggests that priority should be given to developing and refining surveillance programmes which are integrated, comprehensive, timely, and responsive to emerging public health priorities ${ }^{10}$; providing specialist and reference microbiological services for STI agents, and ensuring novel and robust diagnostic technologies are evaluated and applied in cost effective and evidence based manner to improve disease prevention and control activities. Finally, relationships with key external stakeholders, especially those 
working in HIV/STI prevention and control, should be prioritised.

\section{CONCLUSIONS}

Despite the substantial heterogeneity in diagnosis, treatment, and surveillance systems across the EU, available data indicate that STIs are again on the rise in many EU countries. Gains in STI control may be achieved though greater collaboration at the EU level-specifically through harmonising laboratory diagnostic methods, clinical management of STIs, and sharing innovation in STI prevention interventions across the EU. In addition, the heterogeneity of national STI surveillance systems points to the need for more coordinated approaches to EU-wide surveillance, specifically aimed at agreeing case definitions and developing minimum standards for collecting and disseminating STI surveillance data. ${ }^{10} \mathrm{EU}$ wide coordination is also required in order to confidently interpret EU-wide disease trends. Increasing attention at the EU level will also be required for the identification and management of STI outbreaks.

\section{ACKNOWLEDGEMENTS}

Financial support for this study was provided by the European Commission (DG SANCO), Agreement No SI2.325878 (2001CVG4018): ESSTI-European Surveillance of Sexually Transmitted Infections.

\section{The ESSTI Network: Members of ESSTI Collaborative and Steering Groups}

Austria: Reinhild Strauss, BM for Social Security and Generations, Vienna; Angelika Stary, Outpatient Center for Diagnosis of Infectious Venerodermatological Diseases, Vienna. Belgium: Andre Sasse, Epidemiology Section, Scientific Institute of Public Health, Brussels; Marjan Van Esbroeck, Institute of Tropical Medicine, Antwerp. Denmark: Else Smith, Department of Epidemiology, Statens Serum Institut, Copenhagen; Steen Hoffmann*, Department of Epidemiology, Statens Serum Institut, Copenhagen. Finland: Angela Rose, Department of Infectious Disease Epidemiology, National Public Health Institute (KTL), Helsinki; Pentti Huovinen, Antimicrobial Research Laboratory, National Public Health Institute, Turku. France: Veronique Goulet; Françoise Hamers*, Institut de Veille Sanitaire; Dépt des maladies infectieuses, St Maurice; Patrice Sednaoui, Laboratoire de Bactériologie, Institut Fournier, Paris. Germany: Osamah Hamouda, Infektionsepidemiologie/AIDS-Zentrum, Robert Koch Institut, Berlin; Peter Kohl, Department of Dermatology and Venereology, Neukolln Academic Hospital, Free University of Berlin. Greece: Mina Psichogiou, Hellenic Center for Infectious Diseases Control, Department for Surveillance and Intervention, Athens; Eva Tzelepi, National Reference Center for $\mathrm{N}$ gonorrhoeae, Hellenic Pasteur Institute, Athens. Ireland: Mary Cronin, National Disease Surveillance Centre, Dublin. Italy: Barbara Suligoi*, Laboratory of Epidemiology and Biostatistics, Istituto Superiore di Sanità, Rome; Paola Stefanelli, Dept of Infectious, Parasitic and Immuno-mediated Diseases, Istituto Superiore di Sanità, Rome. Netherlands: Marita van de Laar*, National Institute of Public Health and the Environment (RIVM), Department of Infectious Disease Epidemiology, Bilthoven; Joke Spaargaren, GG and GD Amsterdam, Public Health Laboratory, Amsterdam. Norway: Preben Aavitsland, Norwegian Institute of Public Health, Oslo; Jorgen Lassen, Norwegian Institute of Public Health, Oslo. Portugal: Jacinta Azevedo, Consulta de DST do Centro de Saude da Lapa, Lisbon; Maria Jose Borrego, Centro de Bacteriologia, Instituto Nacional de Saude Dr Ricardo Jorge, Lisbon. Spain: Jesús Castilla, Centro Nacional de Epidemiología, Instituto de Salud Carlos 1ll, Madrid; Julio Vazquez, Centro Nacional de Microbiologia, Madrid. Sweden: Torsten Berglund ${ }^{*}$, Swedish Institute for Infectious Disease Control, Solna; Johan Giesecke*, Swedish Institute for Infectious Disease Control, Solna; Hans Fredlund, Swedish Reference Laboratory for Pathogenic Neisseria, University Hospital, Örebro. UK: Mike Catchpole*, Health Protection Agency Communicable Disease Surveillance Centre, London; Hugh Young*, Scottish Neisseria gonorrhoeae Reference Laboratory (SNGRL), Laboratory Medicine (Microbiology), Edinburgh Royal Infirmary, Edinburgh; Chris Bartlett*, UCL Centre for Infectious Disease Epidemiology, Department of Primary Care and Population
Sciences, London; Cathy Ison*, Department of Infectious Diseases and Microbiology, Imperial College School of Medicine, London; Jodi Cooper, Health Protection Agency Communicable Disease Surveillance Centre, London; Anne Scoular, Scottish Centre for infection and Environmental Health, Glasgow.

${ }^{*}$ Member of ESSTI Steering Group.

\section{Authors' affiliations}

K A Fenton, C M Lowndes, Department of HIV and Sexually Transmitted Infections, Health Protection Agency Communicable Disease

Surveillance Centre, 61 Colindale Avenue, London NW9 5EQ, UK

K A Fenton, Centre for Sexual Health and HIV Research, Departments of Primary Care and Population Sciences, Royal Free and University College Medical School, Mortimer Market Centre, off Capper Street, London WCIE 6AU, UK

\section{REFERENCES}

1 Holmes KK, Sparling PF, Mardh PA, et al. Sexually transmitted diseases. 3rd ed. USA: McGraw-Hill, 1999.

2 Wasserheit J, Aral S. The dynamic topology of sexually transmitted disease epidemics: implication for prevention strategies. J Infect Dis 1996;174:201-13

3 Van der Heyden JH, Catchpole MA, Paget WJ, Stroobant A, European Study Group. Trends in gonorrhoea in nine western European countries, 1991-6. Sex Transm Infect 2000;76:110-6.

4 Adler M, Meheust A. Epidemiology of sexually transmitted infections and human immunodeficiency virus in Europe. J Eur Acad Dermatol Venereol 2000;14:370-7.

5 Van Duynhoven Y. The epidemiology of Neisseria gonorrhoeae in Europe. Microbes Infect 1999; 1:455-64.

6 Panchaud C, Singh S, Feivelson D, et al. Sexually transmitted diseases among adolescents in developed countries. Fam Plann Perspect 2000;32:24-32, 45.

7 Eurostat. Theme: general statistics. Free data. Available at europa.eu.int/ comm/eurostat/, last accessed on 15 January 2004. Eurostat, 2004.

8 Stolte G, Dukers NH, de Wit JB, et al. A summary report from Amsterdam: increase in sexually transmitted diseases and risky sexual behaviour among homosexual men in relation to the introduction of new anti-HIV drugs. Euro Surveill 2002;7:19-22.

9 European Commission. The social situation in Europe 2003, in brief. Brussels: European Commission, 2003.

10 Lowndes CM, Fenton KA, and the European Surveillance of Sexually Transmitted Infections (ESSTI) Network. Surveillance Systems for STIs in the European Union: Facing a changing epidemiology. Sex Transm Infect 2004;80:264-71

11 Chesson HW, Dee TS, Aral SO. AIDS mortality may have contributed to the decline in syphilis rates in the United States in the 1990s. Sex Transm Dis 2003;30:419-24.

12 Green MS, Anis E, Gandacu D, et al. The fall and rise of gonorrhoea incidence in Israel: an international phenomenon? Sex Transm Infect 2003;79:116-8.

13 Hiltunen-Back E, Rostila T, Kautiainen $\mathrm{H}$, et al. Rapid decrease of endemic gonorrhea in Finland. Sex Transm Dis 1998;25:181-6.

14 De Schrijver K, Fenton K, Kiehl W, et al. European trends in gonorrhoea. Eurosurveillance Weekly 2000:4.

15 Berglund T, Fredlund H, Giesecke J. Epidemiology of the reemergence of gonorrhea in Sweden. Sex Transm Dis 2001;28:111-14.

16 Berglund T, Fredlund H, Ramstedt K. Reemergence of gonorrhea in Sweden. Sex Transm Dis 1999:26:390-1.

17 Health Protection Agency, SCIEH, ISD, National Public Health Service for Wales, CDSC Northern Ireland, and UASSG. Renewing the focus. HIV and other sexually transmitted infections in the United Kingdom in 2002. London: Health Protection Agency, 1 November 2003.

18 Johansen JD, Smith E. Gonorrhoea in Denmark: high incidence among HIVinfected men who have sex with men. Acta Derm Venereol 2002;82:365-8.

19 Hoffmann S. The laboratory surveillance system of Chlamydia trachomatis and Neisseria gonorrhoeae infections in Denmark. Euro Surveill $2001 ; 6: 86-90$.

20 Berglund $T$, Unemo $M$, Olcen $P$, et al. One year of Neisseria gonorrhoeae isolates in Sweden: the prevalence study of antibiotic susceptibility shows relation to the geographic area of exposure. Int J STD AIDS 2002;13:109-14.

21 Nicoll A, Hamers FF. Are trends in HIV, gonorrhoea, and syphilis worsening in western Europe? BMJ 2002;324:1324-7.

22 Hiltunen-Back E, Haikala O, Koskela P, et al. Epidemics due to imported syphilis in Finland. Sex Transm Dis 2002;29:746-51.

23 Doherty L, Fenton KA, Jones J, et al. Syphilis: old problem, new strategy. BMJ 2002;325:153-6.

24 Parkes R, Renton A, Meheus A, et al. Review of current evidence and comparison of guidelines for effective syphilis treatment in Europe. Int J STD AIDS 2004; 15:73-88.

25 Pritchard L, Hoile E. Paris syphilis screening campaign extended to selected French towns and cities. Eurosurveillance Weekly 2002:6.

26 Hanquet G. IPH ID team. News on outbreak and infectious diseases. Available at www.Iph.fgov.be/epidemio/epien/Issue 19-25 March 2003. 
27 Van de Laar MJ, van Veen M, Götz H, et al. Continued transmission of syphilis in Rotterdam, the Netherlands. Eurosurveillance Weekly 2003:7.

28 Axelsen N, Smith E, Koch-Hansen GH. Syphilis cases increasing in Denmark 2000-01. Eurosurveillance Weekly 2002:6.

29 Petzoldt D, Jappe U, Hartmann M, et al. Sexually transmitted diseases in Germany. Int J STD AIDS 2002;13:246-53.

30 Marcus U, Hamouda O, Kiehl W. Results from laboratory-based reporting of syphilis in Germany, 2001-2002. Eurosurveillance Weekly 2002:6.

31 ESSTI Country STI Surveillance Lead, personal communication, 2003.

32 Johnson AM, Fenton KA, Mercer C. Phase specific strategies for the prevention, control, and elimination of sexually transmitted diseases: background country profile, England and Wales. Sex Transm Infect 2002;78:i1 25-i132.

33 Fenton K, Nicoll A, Kinghorn G. Resurgence of syphilis in England: time for more radical and nationally co-ordinated approaches. Sex Transm Infect 2001;77:309-10.

34 Wilson JS, Honey E, Templeton A, et al. A systematic review of the prevalence of Chlamydia trachomatis among European women. Human Reproduction Update 2002:8:385-94.

35 Stary A, Tomazic-Allen S, Choueiri B, et al. Comparison of DNA amplification methods for the detection of Chlamydia trachomatis in first-void urine from asymptomatic military recruits. Sex Transm Dis 1996;23:97-102.

36 Smith JS, Robinson NJ. Age-specific prevalence of infection with herpes simplex virus types 2 and 1: a global review. J Infect Dis 2002;186(Suppl 1): S3-28.

37 Kjaer SK, de Villiers EM, Haugaard BJ, et al. Human papillomavirus, herpes simplex virus and cervical cancer incidence in Greenland and Denmark. A population-based cross-sectional study. Int J Cancer 1988;41:518-24.

38 Eskild A, Jeansson S, Jenum PA. [Antibodies against herpes simplex virus type 2 among pregnant women in Norway]. Tidsskr Nor Laegeforen 1999; 119:2323-6.

39 Olsen AO, Orstavik I, Dillner J, et al. Herpes simplex virus and human papillomavirus in a population-based case-control study of cervical intraepithelial neoplasia grade II-III. APMIS 1998;106:417-24

40 Persson K, Mansson A, Jonsson E, et al. Decline of herpes simplex virus type 2 and Chlamydia trachomatis infections from 1970 to 1993 indicated by a similar change in antibody pattern. Scand J Infect Dis 1995;27:195-9.

41 Forsgren $M$, Skoog $E$, Jeansson $S$, et al. Prevalence of antibodies to herpes simplex virus in pregnant women in Stockholm in 1969, 1983 and 1989: implications for STD epidemiology. Int J STD AIDS 1994;5:113-6.

42 Arvaja $M$, Lehtinen $M$, Koskela $P$, et al. Serological evaluation of herpes simplex virus type 1 and type 2 infections in pregnancy. Sex Transm Infect 1999;75:168-71.

43 Lehtinen M, Dillner J, Knekt $P$, et al. Serologically diagnosed infection with human papillomavirus type 16 and risk for subsequent development of cervical carcinoma: nested case-control study. BMJ 1996;312:537-9

44 Hakama $M$, Lehtinen $M$, Knekt $P$, et al. Serum antibodies and subsequent cervical neoplasms: a prospective study with 12 years of follow-up. Am J Epidemiol 1993;137:166-70.

45 Wutzler P, Doerr HW, Farber I, et al. Seroprevalence of herpes simplex virus type 1 and type 2 in selected German populations-relevance for the incidence of genital herpes. J Med Virol 2000;61:201-7.

46 Gil A, Gonzalez A, Dal-Re R, et al. Prevalence of antibodies against varicella zoster, herpes simplex (types 1 and 2), hepatitis $B$ and hepatitis $A$ viruses among Spanish adolescents. J Infect 1998;36:53-6.

47 Garcia-Corbeira P, Dal-Re R, Aguilar L, et al. Is sexual transmission an important pattern for herpes simplex type 2 virus seroconversion in the Spanish general population? J Med Virol 1999;59:194-7.

48 De Ory F, Pachon I, Echevarria JM, et al. Seroepidemiological study of herpe simplex virus in the female population in the autonomous region of Madrid, Spain. Eur J Clin Microbiol Infect Dis 1999;18:678-80.

49 Pasquini P, Mele A, Franco E, et al. Prevalence of herpes simplex virus type 2 antibodies in selected population groups in Italy. Eur J Clin Microbiol Infect Dis 1988;7:54-6
50 Franco E, Caprilli F, Zaratti L, et al. Prevalence of antibodies to herpes simplex virus type 1 in different population groups in Italy. Eur J Clin Microbiol 1987;6:322.

51 Jha PK, Beral V, Peto J, et al. Antibodies to human papillomavirus and to other genital infectious agents and invasive cervical cancer risk. Lancet 1993;341:1116-8.

52 Koutsky LA, Galloway DA, Holmes KK. Epidemiology of genital human papillomavirus infection. Epidemiol Rev 1988;10:122-63.

53 Roman A, Fife KH. Human papillomaviruses: are we ready to type? Clin Microbiol Rev 1989;2:166-90.

54 Schiffman MA, Brinton LA, Devesa SS, et al. Cervical cancer. In Schottenfeld D, Fraumeni Jr J, eds. Cancer epidemiology and prevention 1996:1090-116.

55 Burk RD, Kelly P, Feldman J, et al. Declining prevalence of cervicovaginal human papillomavirus infection with age is independent of other risk factors. Sex Transm Dis 1996;23:333-41

56 Cuzick J, Szarewski A, Terry G, et al. Human papillomavirus testing in primary cervical screening. Lancet 1995;345:1533-6.

57 Baver HM, Hildesheim A, Schiffman MH, et al. Determinants of genital human papillomavirus infection in low-risk women in Portland, Oregon. Sex Transm Dis 1993;20:274-8

58 Figueroa JP, Ward E, Luthi TE, et al. Prevalence of human papillomavirus among STD clinic attenders in Jamaica: association of younger age and increased sexual activity. Sex Transm Dis 1995;22:114-8

59 Karlsson R, Jonsson M, Edlund $K$, et al. Lifetime number of partners as the only independent risk factor for human papillomavirus infection: a populationbased study. Sex Transm Dis 1995;22:119-27.

60 Kenney JW. Risk factors associated with genital HPV infection. Cancer Nurs 1996;19:353-9.

61 Cuzick J, Beverley E, Ho L, et al. HPV testing in primary screening of older women. Br J Cancer 1999:81:554-8.

62 Jamison JH, Kaplan DW, Hamman R, et al. Spectrum of genital human papillomavirus infection in a female adolescent population. Sex Transm Dis 1995;22:236-43

63 Hippelainen $M$, Syrjanen S, Koskela $\mathrm{H}$, et al. Prevalence and risk factors of genital human papillomavirus (HPV) infections in healthy males: a study on Finnish conscripts. Sex Transm Dis 1993;20:321-8.

64 Kataoka A, Claesson U, Hansson BG, et al. Human papillomavirus infection of the male diagnosed by Southern-blot hybridization and polymerase chain reaction: comparison between urethra samples and penile biopsy samples. reaction: comparison between
$J$ Med Virol 1991;33:159-64.

65 Grussendorf-Conen EI, Meinhof W, de Villiers EM, et al. Occurrence of HPV genomes in penile smears of healthy men. Arch Dermatol Res 1987:279:S73-S75.

66 Johnson AM, Mercer CH, Erens B, et al. Sexual behaviour in Britain partnerships, practices, and HIV risk behaviours. Lancet 2001;358:1835-42.

67 Wellings K, Nanchahal K, Macdowall W, et al. Sexual behaviour in Britain: early heterosexual experience. Lancet 2001;358:1843-50.

68 Dodds J, Nardone A, Mercey D, et al. Increase in high risk sexual behaviour among homosexual men, London 1996-8: cross sectional, questionnaire study. BMJ 2000;320:1510-1.

69 Laporte A. A new decline in preventive behaviours among homosexual men: the role of highly active antiretroviral therapy? Euro Surveill 2002;7:15-6

70 Department of Health. The national strategy for sexual health and HIV London: DoH, 2001:1-53.

71 Department of Health. The national strategy for sexual health and HIV implementation action plan. London: DoH, 2002

72 All-Party Parliamentary Group on AIDS. Migration and HIV: improving lives in Britain. July 2003. Available at www.appg-aids.org.uk/Publications/ Migration\%20and\%20HIV\%2Olmproving\%20Lives.pdf.

73 World Health Organization. CISID-the Computerized Information System for Infectious Diseases. Geneva: WHO Regional Office for Europe, 2004.

\section{STI email address}

Please note the STI email address has changed from mdimler@bmigroup.com to sti@bmigroup.com. Please use the new email address for any future correspondence. 